\title{
Aprendizagem nas organizações: Uma (re)visão
}

\author{
Learning within organizations: A (re)view
}

Rogério Faé

Psicólogo, Doutor em Administração, professor adjunto na Escola de Administração da Universidade Federal do Rio Grande do Sul (EA/ UFRGS), Porto Alegre, RS - Brasil, e-mail:rfae@ea.ufrgs.br

Recebido: $21 / 12 / 2010$ Received: $12 / 21 / 2010$

Aprovado: $26 / 05 / 2011$ Approved: 05/26/2011

\section{Resumo}

O objetivo do presente artigo é contribuir para a compreensão do processo de aprendizagem organizacional, a partir do exame dos principais referenciais teóricos que abordam o tema e, por fim, valorizar um processo reflexivo que considere a aprendizagem sob premissas que destaquem não apenas os aspectos objetivos e funcionais, mas, principalmente, como processo erigido por premissas estruturais, relacionais e políticas definidoras do contexto de aprendizagem. Nesse sentido, o referencial predominante defende que o desafio da aprendizagem organizacional se impõe sempre que a resposta a uma dada situação organizacional, vivenciada como problemática, exige que os atores que irão participar conjuntamente na busca de soluções construam uma representação compartilhada desta situação. Desafio que, para ser adequadamente enfrentado, requer intenso processo de trocas intersubjetivas com vistas à construção de sentidos comuns. Entretanto, a aprendizagem organizacional é predominantemente valorizada como um processo que visa ao aumento da eficácia, medida por indicadores objetivos, sem que as características estruturais ou relacionais sejam adequadamente valorizadas. Ao término do texto, busca-se a valorização da aprendizagem organizacional como construção relacional que possibilita aos sujeitos a participação em determinado contexto e que busca definir, inclusive, as percepções possíveis aos atores sociais.

Palavras-chave: Aprendizagem organizacional. Relações interpessoais. Reflexividade.

\begin{abstract}
The aim of this paper is to contribute to the understanding of the process of organizational learning, based on the exam of the main theoretic referentials about the theme and, finally, to value a reflective process that considers learning under assumptions that value not only objective and functional aspects, but, mainly, as a process built on structural, relational and political assumptions that define the characteristics of the learning context. In this sense, the prevalent theoretic referentials argue that the challenge of organizational learning always imposes itself when response to a given organizational situation experienced as problematic requires that the actors, who will participate together in the search for solutions, build a shared representation of this situation. A challenge that, to be adequately addressed, requires an intense process of intersubjective interactions in order to construct common meanings. However, organizational learning is
\end{abstract}


primarily valued as a process with a view to improving efficiency, which is measured by objective indicators, without the structural or relational characteristics being properly valued. At the end of the present work, we seek to value organizational learning as a relational construction that enables subjects to participate in a given context and which seeks to define, including, the possible perceptions to social actors.

Keywords: Organizational learning. Interpersonal relationships. Reflexivity.

\section{Introdução}

Busca-se, ao longo do texto, examinar as principais construções teóricas que abordam o tema da aprendizagem organizacional. Os principais aportes teóricos que fornecem as premissas nas quais se ancoram os conceitos atuais são apresentados na primeira parte do texto.

Na segunda parte, ganha destaque o conceito de aprendizagem organizacional como processo, ao correlacionar os microprocessos (individuais e grupais) com os macroprocessos (organizacionais); correlação a partir da qual ganha ênfase uma relação estrutural-relacional dinâmica.

Após, o processo de aprendizagem organizacional é problematizado, ao ser analisado sob a lógica exclusiva da eficiência, medida por indicadores e mecanismos objetivos qualificados como científicos. Momento em que ganha destaque um processo que busca valorizar as condições sob as quais os processos de aprendizagem são construídos, assim como a importância da reflexão como recurso a partir do qual as convicções e/ou práticas podem ser alteradas, com vistas ao alcance de posições mais esclarecidas ou que consigam direcionar os esforços para ações com melhores possibilidades de articular objetivos e/ou interesses individuais, grupais e organizacionais.

\section{Uma rápida revisão da teorização sobre aprendiza- gem organizacional}

Argyris (2005, p. 101), em relação à aprendizagem organizacional, argumenta que um de seus principais objetivos refere-se à possibilidade de que os indivíduos venham a "assumir responsabilidades ativas pelos próprios comportamentos, desenvolver e compartilhar informações de primeira qualidade a respeito do seu trabalho e fazer bom uso do empowerment genuíno para moldar soluções duradouras para problemas fundamentais".

Argyris e Schön (1996) defendem a tese de que o processo de aprendizagem pode ser diferenciado entre ciclo simples - single loop - e ciclo duplo - doble loop. Ciclo simples caracteriza-se pela aprendizagem na categoria instrumental; aprendizagem de ciclo duplo discute a mudança em relação aos valores que embasam determinadas práticas instrumentais. Os autores diferenciam, ainda, as expressões "teoria esposada" e "teoria em uso", identificando a primeira com o discurso corrente, que justifica nossas ações, e a segunda, com as nossas ações reais, embasadas em valores e crenças. A aprendizagem em ciclo duplo tem o objetivo de avaliar ou, pelo menos, tornar conhecida a teoria em uso. Assim, a revisão da teoria em uso da organização pode levar a um repensar a respeito das crenças e/ou modelos mentais subjacentes às práticas evidenciadas (Argyris \& Schön, 1996).

Nessa mesma linha, Senge (1997) define duas formas de aprendizado: $o$ adaptativo e o generativo. 0 aprendizado adaptativo lida com a adequação ao ambiente, e o aprendizado generativo valoriza a criação, a inserção de novos valores e crenças, fundamentadas numa visão sistêmica de mundo.

Senge (1998) sugere cinco disciplinas que facilitariam o processo de aprendizagem generativo:

a) domínio pessoal, que se baseia na crença de que as organizações só aprendem por meio das pessoas, sendo necessário proporcionar aos integrantes da organização condições para formarem uma visão pessoal com relação aos eventos, bem como a manutenção de certa tensão que provoque o movimento pessoal na busca de alternativas aos problemas enfrentados;

b) modelos mentais, que podem ser identificados com valores, ideias ou imagens que dão 
suporte à forma como interpretamos o mundo, dos quais podemos ou não ter consciência;

c) visão compartilhada, que trata da construção de visões ou de objetivos comuns a um determinado grupo, assim como a definição de caminhos que serão partilhados;

d) aprendizagem em equipe, que é o processo de aquisição coletiva de conhecimentos, habilidades e atitudes que são colocados em prática e disseminados ao macrossistema;

e) visão sistêmica, que se refere à possibilidade de enxergar o todo sem abrir mão das partes e da valorização das interrelações microssistêmicas.

Tsang (1997) destaca que os referenciais acima, categorizados sob a denominação de aprendizagem organizacional, estão predominantemente preocupados com os indivíduos e/ou grupos que aprendem. Entretanto, estes não necessariamente colocarão em prática o aprendizado adquirido; por sua vez, as organizações de aprendizagem têm como foco o entendimento da construção, da aplicação funcional e da avaliação da contribuição da aprendizagem no contexto organizacional.

Nessa perspectiva, Sweringa e Wierdsma (1995) entendem aprendizagem como sinônimo de mudança de conduta, que objetiva o aprimoramento de comportamentos que facilitem o alcance das metas a que os atores se propõem. Os autores sugerem, ainda, que a aprendizagem pode ocorrer de três formas: informal, formal e técnica.

A aprendizagem informal consiste em adquirir habilidades de outras pessoas por meio de experiências práticas e/ou por imitação; a aprendizagem formal é aquela que ocorre por meio de recompensas e castigos. Essas duas primeiras formas de aprendizagem frequentemente ocorrem de maneira inconsciente, pois não há, necessariamente, um investimento metódico no processo de aprendizagem (Sweringa \& Wierdsma, 1995).

$\mathrm{Na}$ aprendizagem técnica, há envolvimento consciente e de forma metodológica no processo de aprendizagem. Segundo os autores, nada impede que os processos imitativos ou com base em recompensas e/ou punições possam ser incluídos no rol de técnicas utilizadas nesta última forma de aprendizagem.

Sweringa e Wierdsma (1995) defendem que a aprendizagem organizacional somente pode ocorrer por meio das pessoas que integram a organização. Entretanto a aprendizagem individual não será, necessariamente, ampliada para o grau organizacional, já que uma organização somente aprende quando alguém passa a realizar suas atividades de forma mais eficaz, assim como, quando em consequência deste novo comportamento, o fazer de outros membros é alterado. Somente nesse momento é que podemos falar de aprendizagem coletiva.

Em relação à aprendizagem coletiva ou organizacional, Sweringa e Wierdsma (1995), ao revisar o referencial de Argyris e Schön (1996), postulam a existência de três ciclos de aprendizagem: ciclo único, que provoca alterações nas regras existentes; ciclo duplo, que requer, além das mudanças em relação às regras, insights sobre os porquês de tais normas, que podem levar ao conhecimento e entendimento coletivos a respeito de suas razões organizacionais; e ciclo triplo, que irá pôr em discussão os princípios essenciais sobre os quais se fundamenta a organização.

Na mesma perspectiva dos autores anteriormente, ou seja, buscando explicar a forma como as organizações se desenvolvem, Garvin (1999), com base nos referenciais ligados à qualidade total, afirma que a aprendizagem é um requisito indispensável para a melhoria contínua.

Aopensar a questão daaprendizagem, Garvin (1999) define três fatores críticos a serem considerados:

a) definição do termo 'organizações que aprendem' de maneira plausível, bem fundamentada e que seja conversível em ação e facilmente aplicável;

b) gestão, que se traduz em orientações claras a respeito de aspectos práticos;

c) mensuração, que está ligada à definição de instrumentos que possam avaliar a velocidade e os graus de aprendizado da organização.

Esse autor define que as organizações que aprendem são hábeis em cinco atividades principais:

a) solução de problemas de maneira sistemática, que se fundamenta na confiança em métodos estatísticos, insistência em dados e utilização de ferramentas simples;

b) experimentação, que é identificada com a procura e a testagem de novos conhecimentos, por métodos científicos e da solução de forma sistemática dos problemas;

c) aprendizado com as próprias experiências, que se destina à análise dos resultados organiza- 
cionais de maneira sistemática e com o conhecimento de todos os envolvidos no processo avaliado;

d) aprendizado com outros, que se refere à observação do ambiente externo com vistas à identificação, adequação e incorporação de práticas setoriais bem sucedidas;

e) transferência de conhecimentos, que se traduz na disseminação do aprendizado com rapidez e eficiência por toda a organização.

Garvin (1999) identifica, ainda, três estágios de mensuração em relação ao aprendizado organizacional. A fase cognitiva, na qual são oferecidas novas ideias, objetivando a ampliação de conhecimentos, concentrando o foco da avaliação na profundidade da compreensão e nas atitudes, por meio da aplicação de questionários e de entrevistas. A fase comportamental, que objetiva a internalização de novas ideias e a alteração comportamental das formas de mensuração previstas anteriormente, acrescentando na avaliação a observação do comportamento na organização. A fase de melhoria do desempenho, na qual se espera obter graus mais elevados de eficiência e eficácia no trabalho, com as melhorias observadas nas etapas anteriores. Nesta última etapa, "a auditoria do aprendizado efetivamente abrangente também mensura o desempenho" (Garvin, 1999, p. 76).

Pelos estudos examinados, ficam evidentes as diferenças existentes entre as correntes apresentadas. Percebe-se que o conceito de aprendizagem nas organizações ainda não está completamente definido, havendo necessidade de uma abordagem processual da aprendizagem organizacional, já que ela só passa a ter sentido para os estudos organizacionais clássicos quando associada à mudança (Ruas \& Antonello, 2003).

\section{Processo de aprendizagem}

Os processos de aprendizagem nas organizações são relevantes para as teorias de mudança organizacional, não só ao valorizar a tendência à mudança contínua nas organizações, como também ao propor o entendimento integrado de diferentes categorias de análise, desde o individual, passando pelo grupal e o organizacional (Ruas \& Antonello, 2003).

A forma como se dá o processo de aprendizagem tem sido uma das preocupações atuais no tema aprendizagem organizacional, uma lacuna já levantada por Prange (2001), principalmente no que se refere aos microprocessos de aprendizagem - referentes aos diversos grupos/indivíduos existentes dentro da organização - em contraposição ao aprendizado da organização como um todo (macroprocessos). 0 maior entendimento com relação aos microprocessos pode contribuir para a construção e proposição de novas práticas que aperfeiçoem os processos de aprendizagem nas organizações (Ruas \& Antonello, 2003). Esses autores sugerem a inclusão de novas unidades de análise, tais como processos de grupos ou de comunidades de prática, o que contribuiria para reduzir as deficiências da literatura sobre a relação aprendizagem individual e aprendizagem organizacional.

As organizações possuem uma tendência à estabilização, e a possibilidade de mudança e de aprendizagem se dá a partir do surgimento de questões problemáticas que movimentam os seres, grupos ou organizações, em busca de novos momentos de estabilidade. Essa abordagem é semelhante à de Maturana e Varela (2001), quando discutem o funcionamento do cérebro.

Nesse sentido, pensa-se a possibilidade do aprendizado por dois caminhos: 1) por meio de problemas que surjam na prática do dia a dia, ou 2) por meio do levantamento de questões de forma cognitiva que provoquem um repensar. A diferença entre elas está na forma como o processo é iniciado, se na prática vivenciada ou se na teoria adquirida.

Conforme proposto por Kolb (1997), a aquisição de teoria ou de novas práticas, quando incorporadas, levará à atualização de outros fatores, à observação e reflexão e ao teste em novas situações, conforme demonstrado na Figura 1:

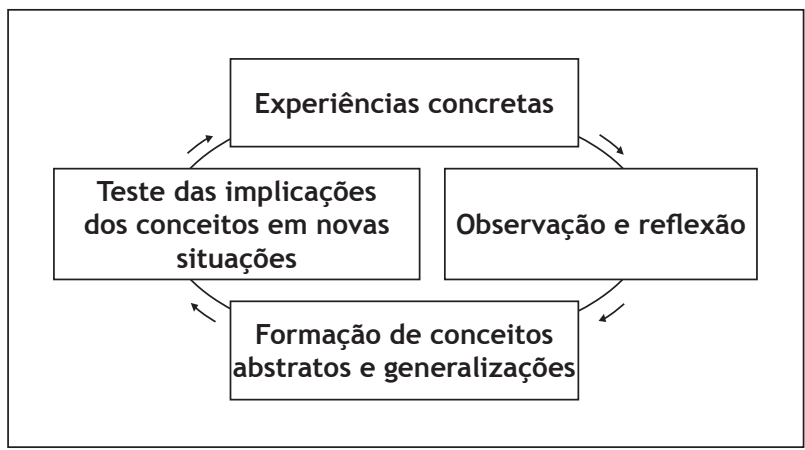

Figura 1 - Ciclo de aprendizagem vivencial Fonte: Kolb (1984). 
Kolb (1997) define duas dimensões básicas no processo de aprendizagem, como processos complementares e inseparáveis: a experiência concreta de eventos e a conceituação abstrata. $\mathrm{O}$ autor defende, com base em Bruner e seu interacionismo simbólico, que a possibilidade criativa é definida pela capacidade que cada indivíduo tem de experimentar formas novas, liberadas de conceitos abstratos anteriores, para que na etapa seguinte possa haver a construção de um sistema reflexivo interiorizado. Por outro lado, considera também a posição de Kagan et al. (citado por Kolb, 1997), ao valorizar a abstração existente no processo de aprendizagem, já que "[...] orientações altamente ativas em relação a situações de aprendizagem inibem a reflexão, impedindo, portanto, o desenvolvimento de conceitos analíticos" (Kolb, 1997, p. 324). 0 ciclo de Kolb permite verificar "uma constante sistematização da interação entre ação e reflexão, experiências passadas e atuais em um processo de permanente feedback" (Ruas, 2001, p. 260).

Nonaka e Takeuchi (1997), por sua vez, valorizam a questão do conhecimento, definindo-o como: ligado a crenças e compromissos dos sujeitos, relacionado à ação, específico ao contexto, e relacional.

Os autores atribuem, com base em Polanyi (1966), duas formas ao conhecimento: tácito e explícito. Este último autor define o conhecimento tácito como pessoal, específico ao contexto e, em consequência, difícil de ser formulado e comunicado; por outro lado, o conhecimento explícito caracteriza-se como transmissível de maneira formal e sistemática.

Para Nonaka e Takeuchi (1997), a produção do conhecimento tácito dá-se no "aqui e agora", imerso num contexto prático específico, e seu compartilhamento com outros indivíduos ocorre a partir da comunicação, que se caracteriza por ser uma forma de processamento simultâneo dos problemas compartilhados pelos indivíduos. 0 conhecimento explícito, por sua vez, valoriza acontecimentos do "lá e então", ou seja, aspectos do passado, e está orientado por uma teoria.

Os autores entendem que o conhecimento é criado por meio da interação entre o conhecimento tácito e o conhecimento explícito, e postulam quatro modos de produção de conhecimento, ilustrados na Figura 2: (1) socialização, caracterizada como produção de conhecimento tácito a partir de conhecimento tácito; (2) externalização, de conhecimento explícito a partir de conhecimento tácito; (3) combinação, de conhecimento explícito a partir de conhecimento explícito; e (4) internalização, de conhecimento tácito a partir de conhecimento explícito.

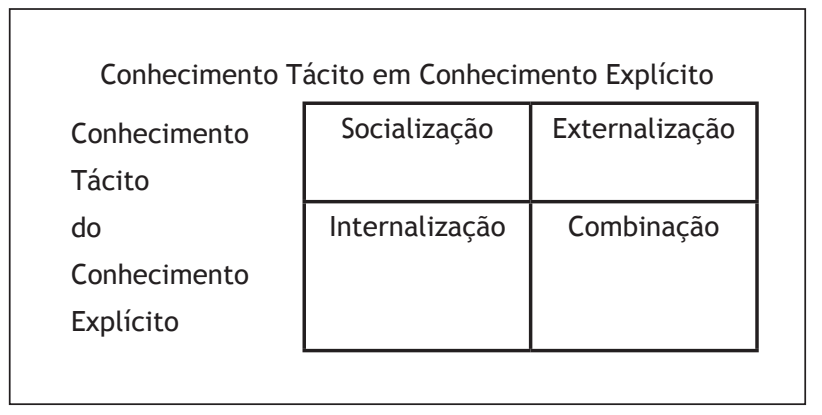

Figura 2 - Modos de conversão do conhecimento

Fonte: Nonaka \& Takeuchi (1997).

Para Nonaka e Takeuchi (1997, p. 79), a inovação, ou criação de conhecimento organizacional, é resultado da interação dinâmica e contínua entre os conhecimentos tácito e explícito, sendo moldada "pelas mudanças entre diferentes modos de conversão do conhecimento que, por sua vez, são induzidos por vários fatores".

Os autores salientam, ainda, a importância do aspecto relacional entre os diversos modos de conversão do conhecimento, que iniciam, normalmente, por meio da socialização, pela abertura de um espaço interativo que facilita o compartilhamento das experiências e modelos mentais dos membros. Em consequência desse compartilhamento, ocorre a externalização, por diálogo ou reflexão coletiva, que leva os indivíduos a articularem o conhecimento tácito. Como resultado de uma articulação bem sucedida e significativa, ocorrem a combinação e a criação de novos conhecimentos, que são mesclados aos conhecimentos já existentes, formando, assim, uma "rede" que se cristaliza em um novo produto, serviço ou sistema. Por último, a transformação desses conhecimentos em práxis provoca novas internalizações.

Assim, o conhecimento atravessa os várias categorias: individual, grupal, organizacional, podendo chegar ao interorganizacional, assim como abrange as dimensões tácita e explícita, sendo esse processo denominado pelos autores de "espiral de criação do conhecimento organizacional” (Nonaka \& Takeuchi, 1997, p. 82).

Já Raelin (1997) busca entender o processo individual de aprendizagem no trabalho por meio da diferenciação entre conhecimento e aprendizagem e da incorporação da oposição explícito versus 
tácito, como formas de conhecimento ao referencial de Kolb (1997), que pressupunha a oposição teoria versus prática em relação à aprendizagem.

Raelin (1997) buscou dar uma contribuição epistêmica a partir do exame das intersecções entre as dimensões conhecimento e aprendizagem, que resulta em quatro tipos específicos de aprendizagem - teórico x prático e tácito x explícito - nas categorias coletiva e individual. $\mathrm{O}$ autor atribui, ainda, ao conhecimento, uma mobilidade dinâmica em que as formas tácito-explícito mutuamente se influenciam de maneira semelhante à proposta por Kolb (1997) à aprendizagem.

Com base nisso, propõe o Modelo de Aprendizagem baseado no trabalho - Work-Based Learning -, conforme Figura 3.

Partindo dos pressupostos anteriores, Raelin (1997) define estilos de aprendizagem conforme a predominância de uma ou outra dimensão em cada contexto, considerando que a variação se dá na predominância, não sendo possível a existência de apenas uma das dimensões.

Nesse sentido, para Ruas e Antonello (2005), o conceito de aprendizagem é entendido como a aquisição, por parte do indivíduo, de determinadas características que poderão ou não ser externalizadas, dependendo das circunstâncias internas ao sujeito e, também, das características do ambiente, que tanto podem facilitar a utilização dessas aquisições como impedir seu aparecimento.

Duguid e Brown (2001), por sua vez, ao versarem a questão do conhecimento, defendem a tese de que a teorização é uma prática entre outras e entendem que as organizações possuem a habilidade necessária para lidar de maneira funcional com ela. Entretanto entre a prática teórica e a prática gerencial, há uma substancial diferença em relação ao exercício operacional.

Assim, os autores, ao considerarem que, no ambiente de trabalho, o engajamento se dá predominantemente por vias não teóricas, defendem que tais posturas decorrem do fato de que as práticas predominantes se caracterizam como práticas sociais, ou seja, "práticas que unem as pessoas mediante atividade interdependente" (Duguid \& Brown, 2001, p. 63). Eles se posicionam, então, de forma a valorizar a noção de comunidade de prática,

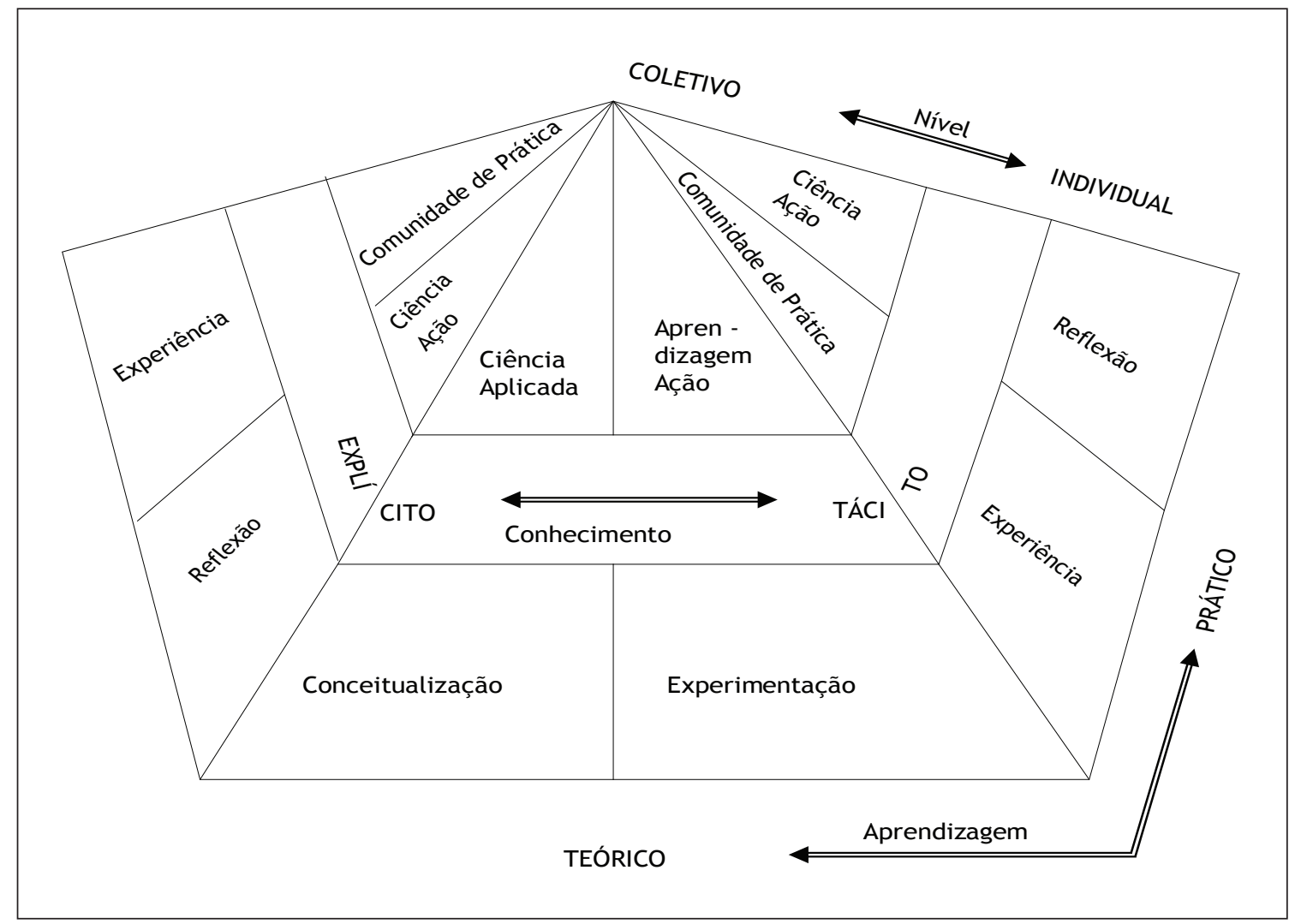

Figura 3 - Modelo de aprendizagem baseado no trabalho

Fonte: Raelin (1997). 
como mecanismo que potencializa a geração de conhecimento a partir de uma visão conjunta de mundo, embasada na construção de uma identidade pessoal compartilhada.

Identidade que, para Wenger (1998), é definida por três formas de pertencimento às comunidades: engajamento, imaginação e alinhamento. 0 engajamento em determinada comunidade de prática abre as possibilidades para partilhar uma visão de mundo que, por um lado, convida a um processo de identificação que proporciona o reconhecimento por parte do grupo social e, por outro, incentiva um determinado fluxo contínuo de conhecimentos e normas sociais que visam a definir quem somos a partir dos aspectos culturais preexistentes à comunidade.

Lave e Wenger (1991) dão centralidade ao processo de engajamento, ao explicitarem seu entendimento com relação à forma como ocorre a entrada de novos membros que, inicialmente periféricos à comunidade, passam a ser reconhecidos e integrados conforme os valores e competências coletivos vão sendo incorporados pelo iniciante. Processo que resulta em uma uniformidade quanto à forma de pensar e agir do grupo social.

Imaginação está ligada ao processo de transcendência em relação à comunidade única, que, por meio do contato com outras comunidades ou com base em experiências anteriores, possibilita a criação de novas perspectivas futuras, criando dinamismo na identidade, assim como possibilidade contínua de novas construções e produções (Wenger, 1998).

Por outro lado, alinhamento, para o autor, vincula-se à possibilidade de, a partir do engajamento com determinadas comunidades e da imaginação, optar pelo pertencimento a determinadas comunidades em detrimento de outras, conforme o potencial pessoal de aprendizagem e os interesses individuais.

Entretanto a comunidade de prática caracteriza-se pela informalidade, ou seja, ocorre em um ambiente externo ao local de trabalho, assim como tem por base redes de relação interpessoais (Wenger, 1998; Duguid \& Brown, 2001). Nesse sentido, são citados, como exemplo, os encontros sociais que podem ocorrer após o expediente, no qual os diversos atores trocam informações a respeito de suas atividades. Trocas que viabilizam o contato com novas formas de realização das tarefas diárias no ambiente organizacional.

Turner (1987) fornece os subsídios para a ampliação dessa visão, ao entender o ambiente organizacional como formado por pessoas reunidas em grupos sociais, valorizando a existência, em todo coletivo, de uma identidade social, assim como defende a tese de que seus membros compartilham uma ou várias categorias perceptivas; ou seja, a constituição de um determinado grupo dá-se pelo compartilhamento de percepções comuns, estejam elas relacionadas ou não a formas de atendimento de necessidades e/ou tarefas. Considera, ainda, à semelhança dos teóricos que buscam apropriar os conhecimentos/ aprendizagens à organização, que a formação de um grupo somente tem razão de existir ao fazer emergir potencialidades distintas daquelas provocadas pela ação social individual.

Esse mesmo autor, por outro lado, diz que toda a conduta grupal é social (e, portanto, organizacional), mas nem toda conduta social é grupal. A conduta social pressupõe ações aceitas num determinado ambiente em que o ator está inserido; por outro lado, a conduta grupal pressupõe comprometimento e identificação com valores e objetivos definidos por um determinado grupo.

Nesse sentido, Turner (1987) define três pressupostos básicos, a partir dos quais articula sua teoria: autoconceito, níveis básicos de categorização e postulados valorativos do autoconceito. Autoconceito é definido, simplesmente, como o sistema de atitudes individuais, que se embasa: (1) no plano cognitivo, a partir de níveis básicos de categorização, e (2) no plano qualitativo, dos postulados valorativos.

Os níveis básicos de categorização podem ser diferenciados entre os "do eu" e os "do não eu". Os primeiros abrangem todas as representações que uma pessoa pode experimentar, enquanto participante de determinado grupo social (por exemplo: professor, brasileiro, etc.). 0 segundo refere-se àquelas categorias com as quais o sujeito não pode ser identificado. Entre as categorias pertencentes ao "do eu", é considerada "saliente" aquela que depende da situação experimentada a cada momento (por exemplo: ao escrever este texto, quem o redige se identifica com o papel de autor).

0 postulado valorativo é o determinante da dinâmica de formação ou não dos grupos sociais, já que, segundo González (1997, p. 294), "as categorias do eu (pertencentes ao autoconceito) tendem a ser valorizadas positivamente, a possível emergência de uma autoavaliação negativa cria um estado aversivo".

Assim, a formação dos grupos sociais se dá a partir da identificação em relação a alguma categorização compartilhada, e pode envolver integrantes 
internos ou externos a determinado círculo de participantes. Dessa maneira, emerge a possibilidade de que se priorizem pessoas de fora do círculo de relações mais próximo, em determinado momento (e conforme a categoria saliente), caso as diferenças percebidas entre essas pessoas sejam menores do que as percebidas com as pessoas de seu entorno. Fato que poderá gerar situações conflituosas entre grupos concorrentes, ou mesmo de exclusão de pessoas que passam a ser percebidas como destoantes, quando considerados os interesses coletivos.

Poderíamos, então, acrescentar ao referencial de Duguid e Brown (2001) a existência de um fator político na aprendizagem, que é facilitado pelas comunidades de prática, mas não se limitam a elas. As consequências das identificações e compartilhamentos, que podem ter início tanto em situações formais quanto em informais, serão ampliadas para todas as relações que vierem a existir na organização.

Nesse ponto, salienta-se a importância em entender a aprendizagem, não como esforço que tenha por objetivo único a qualificação de capital humano, ou seja, que busca simplesmente a eficiência que é mensurada e avaliada pelo retorno econômico proporcionado pelo aprimoramento da mão de obra, mas que considere a aprendizagem como um processo que incorpora às questões cognitivas e comportamentais aspectos estruturais, relacionais e políticos, entre outros.

\section{Reflexividade}

Partindo da discussão desenvolvida até aqui com relação às variáveis envoltas no processo de aprendizagem, evidencia-se a importância da reflexão por parte dos atores que lhe influenciam e/ou são por ele influenciados. Cabe destacar que, apesar da importância atribuída à avaliação da aprendizagem em termos objetivos, pouca atenção é direcionada para a reflexão a respeito do processo de aprendizagem (Silva, 2005).

Entretanto, para este último autor, somente pela reflexão é que convicções e/ou práticas podem ser alteradas, com vistas ao alcance de posições mais esclarecidas ou que consigam direcionar os esforços para ações com melhores possibilidades de articular objetivos e/ ou interesses individuais, grupais e organizacionais.

Nesse sentido, a proposta de Bourdieu (1997) pode oferecer algum suporte, pois remete para um conceito de reflexividade que busca não somente entender os interesses objetivados em metas coletivas ou organizacionais, mas também permitir a percepção acerca dos efeitos da estrutura social sobre os sujeitos/grupos que lhe compõem. Entendendo o campo de ação como construção que se formou conforme os interesses que lhe abriram as condições de emergência, busca-se a compreensão da relação que ali se dá entre os diversos atores.

Entendimento que, segundo Bourdieu (1996), torna indissociáveis as classes individual e social, pois o espaço social, como construção relacional que possibilita aos sujeitos a participação em determinado contexto, busca definir, inclusive, as percepções possíveis aos atores sociais.

Cabe destacar, ainda, a importância do conceito de habitus, como "princípio gerador e unificador que retraduz as características intrínsecas e relacionais de um estilo de vida unívoco, isto é, em um conjunto unívoco de escolhas" (Bourdieu, 1996, p. 21-22). 0 habitus, como produto das posições em um espaço social, opera diferenciações entre os sujeitos a partir de suas categorias perceptivas, nas quais, quanto mais próximas as percepções entre os sujeitos, maior será a possibilidade de integração de esforços; assim como, quanto mais distantes as percepções entre atores em relação a uma situação/objeto, menor será a possibilidade de aproximação e posterior construção cognitiva comum.

Assim, o processo de aprendizagem ganha uma nova perspectiva, ou seja, emerge como processo relacional que, atravessado por variáveis econômicas, políticas e comportamentais, objetiva-se de forma cognitiva, podendo oscilar entre a manutenção de determinada estrutura e o questionamento das práticas vigentes, a partir do confronto de percepções que emergem em relação às diferentes situações e interesses que se apresentam no campo.

Aprendizagem, como processo que busca difundir conhecimentos e práticas, se voltaria para uma construção que valorizaria as várias percepções, objetivos e interesses existentes, proporcionando uma revisão do campo, assim como abrindo a possibilidade de alteração na forma tradicional de pensar o processo de aprendizagem.

A reflexividade, ao ser vinculada ao processo de aprendizagem, se traduziria na possibilidade aberta aos sujeitos que compõem o campo de ação em examinar o contexto, de forma a romper com as oposições tradicionalmente percebidas na teorização sobre o tema (por exemplo: indivíduo/sociedade ou individual/coletivo), examinando-as como polos 
integrados de uma mesma realidade que é construída de maneira relacional. Forma esta que reconhece o processo de aquisição individual do conhecimento, mas o entende imerso num contexto social que lhe delimita as condições de aquisição e demonstração do conhecimento disponibilizado.

Assim, se a aprendizagem constitui-se como individual (Argyris, 2005; Argyris \& Schön, 1996; Kolb, 1997; Nonaka \& Takeuchi, 1997; Prange, 2001), essa aquisição cognitiva e comportamental só é possível sob as condições existentes no espaço social em que os atores estão inseridos, e conforme as categorias perceptivas que lhe são possíveis (Turner, 1987; Bourdieu, 1996).

Forma de ver o processo de aprendizagem que posiciona o mundo social como "algo que os agentes sociais têm a fazer, a construir, individual e sobretudo coletivamente, na cooperação e no conflito" (Bourdieu, 1996, p. 27).

\section{Considerações finais}

A aprendizagem como processo de desenvolvimento, independentemente do contexto em que ocorre, possui algumas características em comum, já que as formas como os seres humanos aprendem, em termos cognitivos, não se alteram significativamente ao modificar-se o espaço em que os sujeitos estão inseridos; o que muda são os objetivos a que tais processos estão submetidos e a maneira como as pessoas são valorizadas.

Assim, tais processos de desenvolvimento não perderão sua eficácia caso sua finalidade não esteja justificada em si, ou seja, quando tais práticas não forem disponibilizadas como conhecimento científico neutro, isento de responsabilidade com relação ao seu uso.

Apesar de considerar que o sujeito está imerso em determinado espaço que valoriza práticas facilitadoras de reconhecimento social, com o intuito de formatar identidades aceitas, o papel da educação (por consequência, da aprendizagem organizacional, como um de seus braços operacionais) não deve ter por princípio básico somente a formação de cidadãos comprometidos com práticas sociais determinadas a priori, mas também o desenvolvimento de instrumentos que forneçam subsídios para uma análise crítica que abra o leque de escolhas possíveis aos indivíduos.

Nesse sentido, a avaliação da aprendizagem não pode se limitar aos aspectos propostos por Garvin
(1999), ou seja, aos aspectos cognitivos e comportamentais ligados ao desempenho, principalmente ao serem valorizados de forma individual, mas deve considerar prioritariamente os objetivos a que o processo de aprendizagem se propõe.

Tais objetivos, ao buscar a integração de esforços e definição das formas mais efetivas de alcance, devem ser pensados em conjunto com os sujeitos que serão alvo do processo de aprendizagem, de forma a valorizar as necessidades destes últimos, assim como possibilitar o questionamento da adequação do processo ao ambiente no qual estão inseridos.

Por outro lado, os resultados em relação a esses objetivos e adequações não podem ser avaliados apenas no fim do processo, mas devem ser acompanhados enquanto ele ocorre. 0 acompanhamento terá, assim, uma importância fundamental e maior do que a avaliação final, pois é em meio ao processo que será possível corrigir rotas, com a finalidade de adequar os objetivos a novas necessidades, bem como verificar a adequação dos meios e estratégias aos objetivos.

Cabe salientar que será difícil ocorrerem mudanças significativas e de longo prazo sem que haja questionamentos e possíveis alterações daí resultantes, em relação às lógicas tradicionais que estão enraizadas em determinados padrões cognitivos, comportamentais, políticos e econômicos.

Nesse sentido, torna-se relevante a prática da reflexividade, de maneira a provocar um processo que analise as práticas atuais e forneça ligações entre o processo de aprendizagem e a estrutura social/organizacional preexistente. E é, exatamente, esse repensar que poderá fornecer as bases para o desenvolvimento organizacional e para o conhecimento comum das problemáticas existentes.

Por último, é relevante salientar a importância do incentivo à discussão a respeito da forma como os diversos agentes sociais percebem o processo em que estão inseridos, possibilitando o estreitamento dos laços entre os atores envolvidos, desde aqueles que detêm o poder de direcionar os esforços organizacionais, até aqueles atores que irão operacionalizar as ações. Enfim, entre todos os atores envolvidos no processo de aprendizagem, de forma a alargar os horizontes e incorporar novos olhares que possam contribuir para o processo como um todo, assim como facilitar construções com maior grau de participação, autoavaliação e responsabilização pelos processos de aprendizagem e mudança. 


\section{Referências}

Argyris, C. (2005). A boa comunicação que impede a aprendizagem. In Harvard Bussines Review. Aprendizagem organizacional (pp. 101-122). Rio de Janeiro: Elsevier.

Argyris, C., \& Schön, D. A. (1996). Organizational learning II: Theory, method and pratice. New York: Addison-Wesley.

Bourdieu, P. (1996). Razões práticas: Sobre a teoria da ação. Campinas: Papirus.

Bourdieu, P. (1997). A miséria do mundo. Petrópolis: Vozes.

Duguid, P., \& Brown, J. S. (2001). Estrutura e espontaneidade: Conhecimento e organização. In M. T. M. Fleury, \& M. M. Oliveira Jr., Gestão estratégica do conhecimento: Integrando aprendizagem, conhecimento e competências (pp. 50-85). São Paulo: Atlas.

Garvin, D. A. (1999). Construindo as organizações que aprendem. In: Harvard Business Review. Gestão do conhecimento (pp. 50-81). Rio de Janeiro: Campus.

Gonzáles, M. P. (1997). Orientaciones teóricas fundamentales em psicología de los grupos. Barcelona: EUB.

Kolb, D. A. (1984). Experiential learning: Experience as the source of learning and development. New Jersey: Prentice-Hall.

Kolb, D. A. (1997). A gestão e o processo de aprendizagem. In K. Starkey. Como as organizações aprendem (pp. 321-341). São Paulo: Futura.

Lave, J., \& Wenger, E. (1991). Situated learning: Legitimate peripheral participation. Cambridge: Cambridge University Press.

Maturana, H. A., \& Varela, F. J. (2001). A árvore do conhecimento: As bases biológicas da compreensão humana. São Paulo: Palas Athena.

Nonaka, I., \& Takeuchi, H. (1997). Criação de conhecimento na empresa: Como as empresas geram a dinâmica da inovação. Rio de Janeiro: Elsevier.

Polanyi, M. (1966). The tacit dimension. London: Routledge \& Kegan Paul.
Prange, C. (2001). Aprendizagem organizacional: Desesperadamente em busca de teorias. In: M. Easterby-Smith, \& J. Burgoyne. Aprendizagem organizacional e organização de aprendizagem: Desenvolvimento na teoria e na prática (pp. 41-63). São Paulo: Atlas.

Raelin, J. A. (1997). Model of work based-learning. Organization Science, 8(6), 563-578.

Ruas, R. L. (2001). Desenvolvimento de competência gerenciais e a contribuição da aprendizagem organizacional. In M. T. Fleury \& M. Oliveira Jr. (Org.). Gestão estratégica do conhecimento (pp. 242-267). São Paulo: Atlas.

Ruas, R. L., \& Antonello, C. S. (2003). Repensando os referenciais analíticos em aprendizagem organizacional: Uma alternativa para análise multidimensional. Revista de Administração Contemporânea, 7(3), 203-212.

Ruas, R. L., \& Antonello, C. S. (2005). Formação gerencial: Pós-graduação lato sensu e o papel das comunidades de prática. Revista de Administração Contemporânea, $9(2), 35-58$.

Senge, P. (1997). 0 novo trabalho do líder: Construindo organizações que aprendem. In K. Starkey. Como as organizações aprendem (pp. 343-375). São Paulo: Futura; Zumble.

Senge, P. (1998). A quinta disciplina. São Paulo: Futura; Zumble.

Silva, J. C. S. (2005). Aprendizagem organizacional: Condições e desafios para o desenvolvimento de comunidades de prática em organizações de ensino superior. Tese de Doutorado, Programa de Pós-Graduação em Economia da Universidade Federal da Bahia, Salvador.

Sweringa, J., \& Wierdsma, A. (1995). La organización que aprende. Buenos Aires: Addison-Wesley.

Tsang, E. W. K. (1997). Organizational learning and the learning organizational: A dichotomy between descriptive and prescriptive research. Human Relations, 50(1), 73-89.

Turner, J. C. (1987). Rediscovering the social group: A self-categorization theory. Oxford: Basil Blackwell.

Wenger, E. (1998). Communities of practice: Learning, meaning and identity. Cambridge: Cambridge University Press. 